\title{
The theoretical substantiation of constructive parameters of the vibration digging working body
}

\author{
V. Bulgakov' ${ }^{1}$ I. Holovach ${ }^{2}$ \\ National University of Life and Environmental Sciences of Ukraine, \\ 15 Heroiv Oborony Str., Kyiv, 03041, Ukraine \\ e-mail: ${ }^{1}$ vbulgakov@meta.ua, ${ }^{2}$ holovach.iv@gmail.com \\ ORCID: ${ }^{1}$ 0000-0003-3445-3721, 20000-0003-1387-4789
}

\begin{abstract}
Goal. To substantiate the rational constructive length of the working channel of the vibrating digging working body by interaction with the body of sugar beet root during its digging out of the soil. Methods. Theoretical research was conducted using the basic provisions of the theory of agricultural machinery, higher mathematics, and theoretical mechanics. Numerical calculations and graphical dependencies are obtained using a PC based on developed and standard programs. Results. The calculated scheme of root crop contact with the working body is constructed and the analytical dependence of the number of vibrations of the vibrating digging working body on interaction with the root crop, during its stay in the area of the rear part of the digger working channel, on the length of the rear part digger. Based on the conducted analytical researches the expression for determination of the minimum admissible frequency of fluctuations of a working body under the condition of maintenance of obligatory capture of each root crop by digging plowshares is received. Conclusions. As a result of calculations, it is determined that for the length of the rear part of the working channel of the digger $0.1 \mathrm{~m}$ and the translational speed VP $=2.1 \mathrm{~m} / \mathrm{s}$ the oscillation frequency $\mathrm{n}=20.3 \mathrm{~Hz}$ provides a satisfactory mode of vibratory digging of roots. The frequencies $n=15.7 \mathrm{~Hz}$ and $n=8.5 \mathrm{~Hz}$ have an insufficient effect. At the same length of the rear part of the working channel and translational speed VP $=1.3$ $\mathrm{m} / \mathrm{s}$ the frequencies $\mathrm{n}=20.3 \mathrm{~Hz}$ and $\mathrm{n}=15.7 \mathrm{~Hz}$ provide a satisfactory mode of vibratory digging of roots, and the frequency $n=8.5 \mathrm{~Hz}$ - insufficient (some roots are not removed by the working body or broken in the tail). To ensure a satisfactory mode of vibratory digging of roots at the speed of translational movement of the digger VP $=2.0 \mathrm{~m} / \mathrm{s}$ and the oscillation frequency of the working body $n=10 \mathrm{~Hz}$, it is necessary that the length of the rear of the working channel of the digger is $0.2 \mathrm{~m}$. The range of permissible oscillation frequencies of the working body is determined, which can be recommended for translational speeds in the range of $1.3-2.2$ $\mathrm{m} / \mathrm{s}$, taking into account the limitation of oscillation frequencies of the working body under conditions of obligatory capture of each root crop by digging plowshares.
\end{abstract}

Key words: vibrating working body, root crop, contact interaction, working channel, length. DOI: https://doi.org/10.31073/agrovisnyk202012-07

An important condition to ensure the quality of the technological process of vibratory excavation of sugar beet roots from the soil is that they are not damaged. Obviously, the greatest probability of damage to the root crops and even their breaking takes place in the interaction of the digging working body with the root body of the vibratory contact and its passage in the channel between the planes of the vibratory digger. Since this interaction occurs during the first contact of the vibratory digging working body with the root body, which is still firmly connected with the surrounding soil, and the side surface of the digger (one or both) is active on it, then due to the speed of the progressive movement of the Kopach and the speed of its vibratory motion damage to the root will be even mandatory, especially when digging occurs from dry and solid soil. During such a contact within a fairly short period of time there are conditions that can lead to a complete break-in and loss of the tail of the root.

According to an important question in the theoretical study is to determine the length of the back of the working bed of the vibrating digger, from the point of first contact with the root of the root until the end of the working bed (where the final digging takes place), that is, the length of the working planes of the digger, where there is a constant contact with the root and its direct removal from the soil. Of course, this length may be different (including different design solutions, taking into account the different sizes of root crops, etc.), but it must have some average value $l$, and can be further used in the design of vibratory vicopuvalnyh working planes for sugar beet root crops.

Therefore, there is an actual scientific and technical problem to theoretically investigate the specified interaction of sugar beet root, which is in the soil, with the vicopuvalnimy of the ploughshare of the vibratory vicopouflage working body, which will determine the rational design and kinematic of its parameters in the case of intact (non-invasion) of root crops in this interaction during the vibratory digging.

Analysis of recent research and publications. Sufficiently thorough studies of the process of vibratory digging of sugar beet roots out of the soil have been published in [1 - 7]. In these works the interaction of the vibratory vicodermic working body with the sugar beet root body is considered in detail when providing the last parameters of the vibratory impact, which ensure its digging out of the soil. However, the design features of many structures of vibratory vicopuvalnyh working bodies such that the direct digging out of the soil of the root 
body here occurs in the interaction with various parts of the digger, in particular during its clamping and further passage of the narrowed working channel. In addition, the vibrating vikapivalnye working elements used in many cornezbiralnyh machines manufactured in the world, digging planes (ploughshare) have not only different sizes, but also a different form of working edges (blades), their different location, slopes in space and the like.

In addition, in these articles, the interaction of the body of sugar beet root with the ploughshare of the vibratory digging working device here is considered only one (or two points), but the body of sugar beet root at excavation from the soil consistently comes into contact with different points of the vicopuvalnyh ploughshare at the progressive movement of the vibratory digging working device. These points of contact change both in length and height of the ploughshare, covering the body of the root on both sides. That is, the passage of the bodies of sugar beet root because of the narrowed channel vibratory digging working device, and above all the prerequisites for determining the length of the working channel vibratory digging working device is not considered here.

And, only in [8] and [9] are some results of experimental studies of the frequent interaction of the root body with the digging working device, and this depends not only on the speed of the progressive motion of the digger, but also on the length of the working channel of the vibratory digging working device. All this causes theoretical research, which would make it possible to establish the geometric parameters of the plowshares, which form a vibrating digging working body for the roots of sugar beets. The purpose of the study is to substantiate the rational constructive length of the working channel of the vibratory digging working body when interacting with the sugar beet root body when digging it out of the soil.

Scientific works [10 - 14] are devoted to the research of the technological process and the results of tests of modern beet harvesters and their working bodies. However, a thorough theoretical study to substantiate the parameters of vibrating excavation working bodies is not given here. The study of the working process of the movement of the body of the root of sugar beet inside the excavating plowshares of the vibrating working body is not at all.

Materials and methods. The research was carried out using the basic provisions of the theory of agricultural machinery, higher mathematics and theoretical mechanics. Numerical calculations and graphical dependencies were obtained using a PC based on developed and standard programs.

Results and their discussion. We have developed a new design of vibratory digging working device for sugar beet roots, design and technological scheme and 3D model of which are presented in Fig. 1.
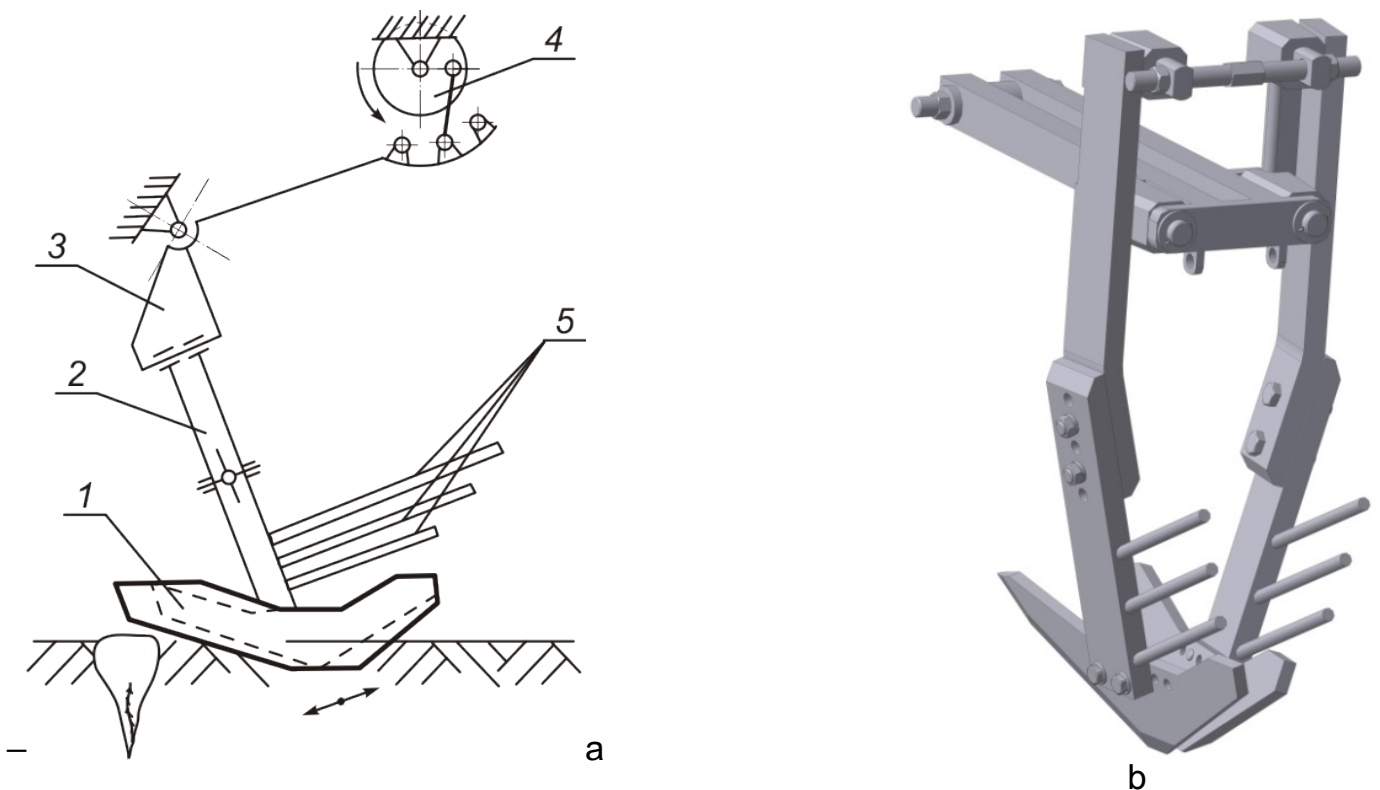

Fig. 1. Structural and technological scheme (a) and computer $3 D$ model (b) of the new vibratory digging working device for sugar beet root crops: 1 - digging ploughshares; 2 - stands 3 mechanism for adjusting the distance between the ploughshares; 4 - vibration drive with a mechanism for adjusting the amplitude and frequency of the ploughshares; 5 -guide pins

For theoretical substantiation of design parameters of the vibratory digging working device we show the main dimensions of its vicopipedal ploughshare and the working channel of the whole digging device (Fig. 2).

As can be seen from the diagram in Fig. 2, the front part of the ploughshare, which is determined by the length $I_{R}$ and complex shape in the longitudinal-vertical plane has sharpening and cutting edges of the blade, is characterized by two corners: $\alpha$ - angle of inclination of the sharp end of the blade to the horizon, and $\beta-$ angle of inclination of the lower edge of the blade to the horizon. Moreover, the angle of slope of sharp edge of the blade end to the horizon (angle $\alpha$ ) is more important than the angle of slope of the lower edge of the blade to the horizon (angle $\beta$ ). It is the front part of the vibratory excavating working device has in the horizontal 
plane the greatest distance between the front ends of the blades, and, accordingly, forms the angle $\theta$ of the front part ("solution") of the working channel of the vibratory excavating working device, which ensures that all the root crops located in a line and having some deviation from the center line. The middle part of the ploughshare, which is determined by the length of the $I_{z}$ - is actually a zone of the first contact between a ploughshare and sugar beet root body, which is actually fixed in the soil for the time being. It is at this length that not only the first contact with the root body occurs, but also its strong clamp in the working bed, gradually narrowing, grabbing and moving further along the narrowed bed of the vibratory digger. In addition, it is this part of the ploughshare has the narrowest channel and slope in the longitudinal-vertical plane, allows for a short period of time and the movement of the working plane of the ploughshare upward with vibratory vibrations to pull the root body out of the soil. Finally, it is the back part of the digging ploughshare, which is characterized by the length of the ploughshare $I_{B}$, having smaller length, these parts of the ploughshares have a tendency to upwards at angles $\gamma$ to the horizon, and the working channel has some difference, because it is in this part of the vibratory digging out working body of sugar beet root should release the vibratory digger for its quick delivery to the cleaning working elements.

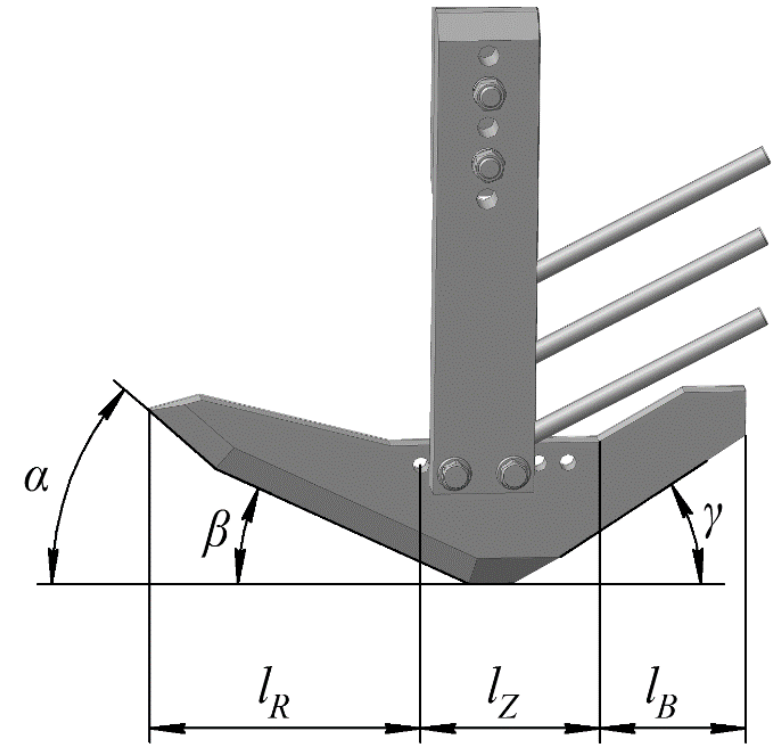

a

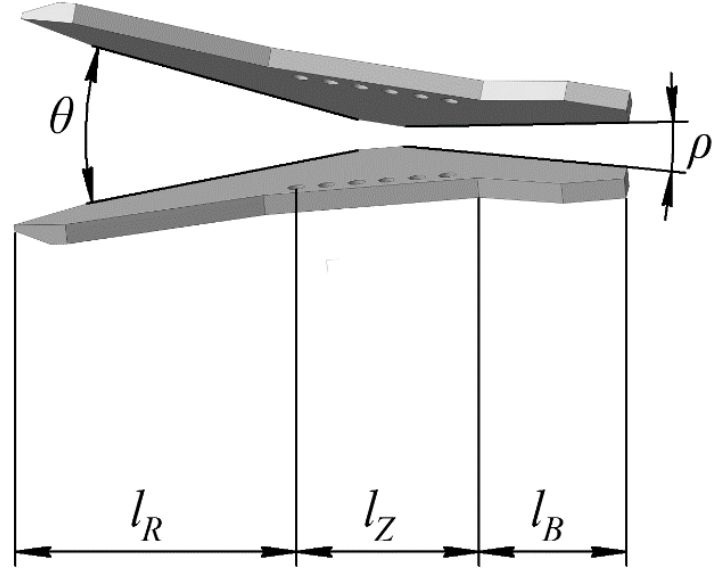

b

Fig. 2. Structural dimensions of the digging ploughshare (a) and the working channel (b) of the vibrating digging working device

To substantiate the design parameters of the vibratory digging working body, primarily its working ploughshares, it is necessary to analytically consider the above-mentioned contact of the root body with the working body and find an analytical dependence of the number of vibrations of the vibratory digging working body in the interaction with the root during its stay in the zone of the working bed from the length of the back of the working bed, the frequency of vibration and the forward speed of the digger. So, if $l$ - the distance from the point of first contact with the root to the end of the working channel digger, and $V_{\Pi}$ - the speed of the progressive motion of the digger, the time of stay of the root in the specified zone of the working channel will be equal:

$$
t_{p}=\frac{l}{V_{\Pi}} .
$$

During this time, the working body will perform so many fluctuations:

$$
k=v \frac{l}{V_{\Pi}},
$$

where $\mathrm{V}$-oscillation frequency of the vibrating working device, $\mathrm{Hz}$

So, for example, if according to [9] it is accepted that $V_{\Pi}=2 \mathrm{~m} / \mathrm{s}, v=20 \mathrm{~Hz}, l=0,1 \mathrm{~m}$ (the minimum possible value of the length of the back part of the working bed), then by expression (2) we get that during the time of the root crop location in the working bed digger working body will make one oscillation, that is $k=1$.

Let's investigate further how many delights of a root can be carried out by a vibrating working device during the time of stay of a root in a back part of a working channel of a digger at $k=1$, i. e. when for this time a working device will carry out one full oscillation. 
Two cases are possible here.

First case: The working body makes its first direct contact with the root at the moment when it moves upwards from the lowest position to the lowest. Let us denote the oscillation period of the impeller in $\tau$. Since the outrageous force in this case will be directed upwards, this first contact of the working body on the root and will be the first delight of the root of the working body, which will begin the process of breaking the bonds with the soil. This delight will continue as long as the implement reaches its highest position. Let us denote this time interval $t_{1}$. Obviously, it will be equal:

$$
t_{1}=s_{1} \tau \text {, }
$$

where $0 \leq s_{1} \leq 0,5$ - is the number that indicates which part of the period will be the first root crop capture by the working device.

For example, if $s_{1}=0,5$, it means that the first delight of the root began in a low position and therefore $t_{1}=0,5 \tau$. So if $s_{1}=0$, it means that the first contact began in a high position, and therefore $t_{1}=0$. All other values of $S_{1}$, which satisfy the specified bump, take into account the beginning of the grip at any time when the implement moves upwards from the lowest position to the lowest.

Upon reaching the high position, the working device starts to move downwards. In this case, given the conical shape of the root, the perturbing force ceases to act on the root, and therefore, the capture of the root does not occur. This will happen over tim $t_{2}=0,5 \tau$, while the working device moves from the high position to the lowest one. After that, the impeller starts moving up again from the lowest position to the lowest.

Consequently, during the time $t_{3}=\tau-\left(t_{1}+t_{2}\right)$ will take place the second capture of the root of the working body, which will begin the further process of destruction of bonds with the soil before direct extraction. Obviously, for the second capture must occur mandatory full extraction of the root from the soil, otherwise the root will remain in the soil (i. e, will occur or its cutting of the oval, or it will take over the working channel digger).

If the root vegetable will be weakly fixed in the soil, it is possible that withdrawal can occur immediately at the first capture by a vibratory digging working device.

Second case: The working body makes the first direct contact with the root at the moment when it moves down from the highest position to the lowest one. This will take place during the time $t_{1}=s_{1} \tau$, where $0 \leq s_{1} \leq 0,5$.

In this case, the root will not be affected by the disturbing force of the vibrating working device. Reaching the lowest position, the vibrating impeller will start moving upwards from the lowest position to the lowest. At this point in time, the first rapture of the root of the impeller, the duration of which is $t_{2}=0,5 \tau$, before the impeller reaches the highest position. Then, the impeller will start to move down and for a period of time $t_{3}=\tau-\left(t_{1}+t_{2}\right)$ on the root again will not act an outrage, that is, in this interval of time also there will be no root delight.

So, in the second case, in the period of time $t_{1}+t_{2}+t_{3}=\tau$ there will be only one capture of the root of the working body, which must necessarily occur complete removal of the root from the soil, otherwise the root will remain in the soil.

However, it is clear that the presence of only one root crop grip at a certain depth, which will contribute to tear off from the surrounding and containing soil, and further movement in the narrowed channel of the digger on the sloping surfaces of the ploughshare will be sufficient to fully extract the root crop.

At $k<1$ (the working body does not have time to make a complete oscillation during the stay of the root in the back of the working stream of the digger) in the first case, only one root can be captured by the working body, in the second - none. Thus, the root crop must be removed after a single seizure of the working device, or, in extreme cases, in the narrowed bed of the digger, due to the progressive movement of the digger (as it happens in a conventional grubby digging working device). However, the removal of firmly fixed in the soil root root in the narrowed channel due to the progressive movement of the digger can lead to a sharp tilt of the root in the direction of the digger's movement and its breakage. Moreover, when $k<1$ firmly connected to the soil root can be in one grip vibratory digging tool can also remain untouched.

Thus, the ratio between the frequency of oscillation of the working device, the progressive speed of the digger and the length of the working channel should be such that the working device during the stay of the root in the back of the working channel managed to make at least one oscillation, that is, it is necessary that $k \geq 1$.

If, for example, $k=2$ (when the length of $l$ back of the working bed of the digger is equal to $0.2 \mathrm{~m}$ ) and there is a first case (the first contact with the root of the working device occurred during the movement of the working device up), then for the period of the first oscillation of the working device will perform two captures of the root, and for the period of the second oscillation - one capture. If there is a second case (the first contact of a working device on a root crop took place at moving of a working device downwards), then for the period of the first and second oscillations a working device will carry out one capture of a root crop. Consequently, at 
$k=2$ either three captures or, in the worst case, two captures of the root.

Of course, the more $k$, the smoother and better will be the process of extracting the root from the soil by a vibratory digging working device, because with more vibrations per root, you can use less perturbing force to extract the root, and therefore reduce the likelihood of rupture of the body of the root. In addition, the greater the $k$, the more vibrations perform the root vegetable together with the working body, and thus the more it will be cleaned from the sticky soil.

As can be seen from expression (2), the increase in number can be achieved either by increasing the frequency of vibrations of the working device and the length of its working channel, or by reducing the progressive speed of the digger. So, having set the number $k(k \geq 1)$ the vibrations of the working device during the body stay in the digging channel, you can always find the relationship between the parameters $v$, $l$ and $V_{\Pi}$ according to expression (2). In particular, for given specific values $l$ and $V_{\Pi}$ from expression (2) we find the necessary frequency of vibrations of the working device, namely:

$$
v=\frac{k V_{\Pi}}{l} \text {. }
$$

Thus, the minimum frequency of vibrations of the working device, which provides the optimal mode of vibratory root excavation. If $k=1$ (one oscillation of the working device during the time of the body stay in the working channel of the digger), then from the expression (3) we get:

$$
v=\frac{V_{\Pi}}{l} \text {. }
$$

If the vibrating frequency of the working device is less than that obtained from expression (4), the mode of vibratory root digging will be broken. This means that some root crops will not be captured by the impeller in the vibrating process, and therefore will not be excluded, or will be broken in the tail part. All this will lead to an undesirable loss of root crops during excavation.

So, the unreasonable relationship between the parameters $k, v, l$ and $V_{\Pi}$ is one of the main reasons for the loss of part of the root crops in existing beet harvesting machines during vibratory digging.

Let's plot (Fig. 3) the dependence of the minimum allowable frequency $V$ of speed $V_{\Pi}$ of the digger progressive motion at $k=1$ and $l=0,10 \mathrm{~m}, l=0,15 \mathrm{~m}$ and $l=0,20 \mathrm{~m}$ according to expression (4).

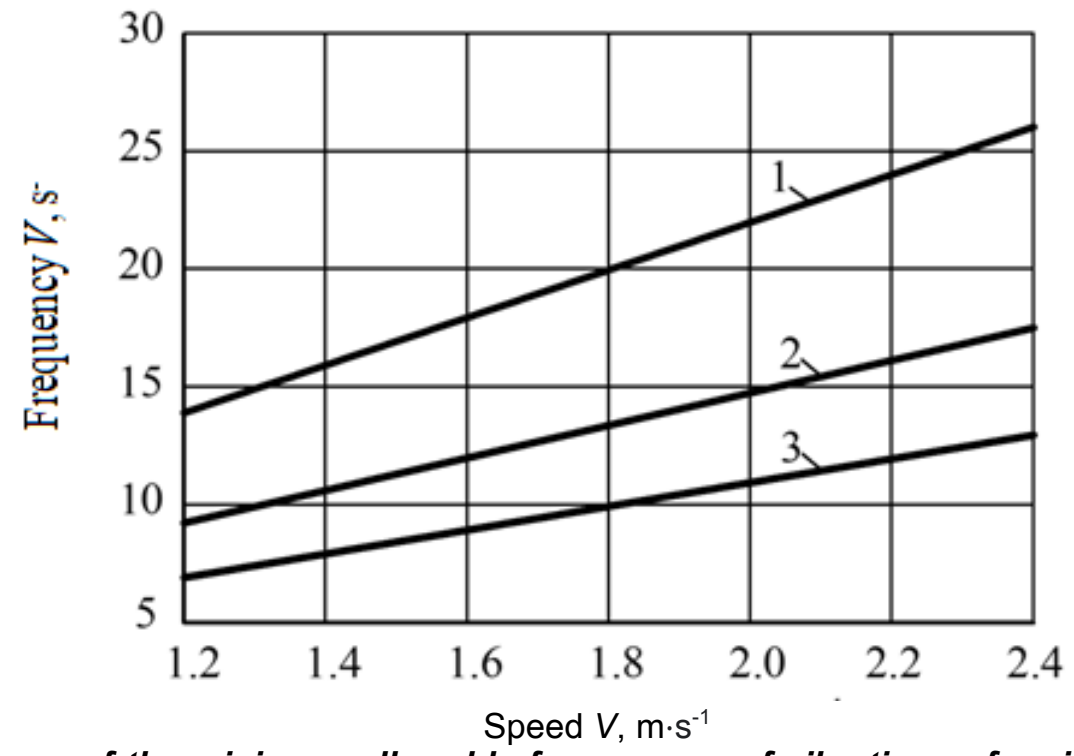

Fig. 3. Dependence of the minimum allowable frequency $v$ of vibrations of a vibrating digging out working device on speed $V_{\Pi}$ of its forward movement at values of length of a back part of a working channel: $1-l=0,10 \mathrm{~m} ; 2-l=0,15 \mathrm{~m} ; 3-l=0,20 \mathrm{~m}$

As can be seen from the diagrams obtained (Fig. 3), with increasing speed of progressive movement of the digger grows the minimum permissible frequency of oscillation of the working device, provides a one-time delight of the root of the working device. At the same time, an increase in the length of the back of the working channel of the digger contributes to a decrease in the minimum allowable frequency of vibrations of the working device. 
So, for each speed value $V_{\Pi}$ Progressive motion of the digger and length / of the back part of the working channel there is a certain value of the minimum frequency, below which the process of vibratory digging of root crops is disturbed, that is, some root crops are not removed by the vibratory digging organ. As can be seen from the graph, at $l=0,1 \mathrm{~m}$, frequency $v=20 \mathrm{~Hz}$ provides satisfactory vibratory process of root excavation for all values of speed $V_{\Pi}$ of the progressive motion of the digger, smaller for $2,0 \mathrm{~m} / \mathrm{s}$, and at = $0.15 \mathrm{~m}$ the frequency $20 \mathrm{~Hz}$ - for all speed values less than $3.0 \mathrm{~m} / \mathrm{s}$. Consequently, at $l=0,1 \mathrm{~m}$, if it is necessary to ensure the speed of the progressive motion of the digger $V_{\Pi}=2,0 \mathrm{~m} / \mathrm{s}$, all the sets of values of admissible frequencies, obtained from the conditions of intactness of the root at the impact interaction with the working body, it is necessary to limit the lower frequency value $v=20 \mathrm{~Hz}$.

So, if for some kinematic modes the received values of admissible frequencies at shock interaction are less than $V=20 \mathrm{~Hz}$, they obviously do not meet the conditions for a satisfactory process of vibratory root excavation with the length of the back part of the working channel $l=0,1 \mathrm{~m}$ and the speed of the digger $V_{\Pi}=2,0 \mathrm{~m} / \mathrm{s}$.

At the same time, if you specify a specific value of the length of the back of the working bed of the digger and the frequency of oscillation of the working body, then from expression (4) it is necessary to determine the maximum allowable speed of $V_{\Pi}$ progressive movement of the digger, which ensures quality digging root crops.

This theoretical reasoning is clearly supported by experimental studies of the mass of lost sugar beet root crops, [9]. For example, at the speed of progressive movement of the digger $V_{\Pi}=2,1 \mathrm{~m} / \mathrm{s}$ and vibrating frequency of the impeller $v=20,3 \mathrm{~Hz}$ weight of lost root crops is $0,7 \%$, at the frequency of $V=15,7 \mathrm{~Hz}-$ $2,5 \%$, at the frequency of $8,5 \mathrm{~Hz}-3,5 \%$.

Therefore, at the travel speed $V_{\Pi}=2,1 \mathrm{~m} / \mathrm{s}$ oscillation frequency $V=20,3 \mathrm{~Hz}$ provides a satisfactory mode of vibratory root excavation, and frequency $v=15,7 \mathrm{~Hz}$ and $v=8,5 \mathrm{~Hz}$ - in other words, some root vegetables are not taken away by the working body or are cracked in the tail part. This is confirmed by the calculation of the expression (4).

At driving speed $V_{\Pi}=1,3 \mathrm{~m} / \mathrm{s}$ and vibration frequency $V=20,3 \mathrm{~Hz}$ mass of lost root crops is $0.5 \%$, at frequency $V=15,7 \mathrm{~Hz}-1,8 \%$, but at frequency $V=8,5 \mathrm{~Hz}-2,8 \%$. So, the frequencies $V=20,3 \mathrm{~Hz}$ and $V=15,7 \mathrm{~Hz}$ provide a satisfactory mode of vibratory root excavation, and frequency $V=8,5 \mathrm{~Hz}$ provides insufficient.

According to [9], in the process of rapid improvement of the vibrating digging working elements of beet harvesters, produced by all leading companies in Europe, the frequency of vibrations of working elements increased

from 3.3...6.0 Hz to $10 \mathrm{~Hz}$, i. e. in the production conditions it is not yet possible to achieve the highest oscillation frequency of $10 \mathrm{~Hz}$ due to the lack of reliability of the mechanism to drive the working element in the oscillatory motion. Therefore, from the above calculations it follows that in order to ensure a satisfactory mode of the process of vibratory root excavation at a speed of progressive movement of the digger $V_{\Pi}=2,0 \mathrm{~m} / \mathrm{s}$ and the frequency of vibrations of the working device $V=10 \mathrm{~Hz}$ it is necessary to have the following ratios between the geometric parameters of the working device, which would provide the length of the back of the working channel of the digger, equal to $0.2 \mathrm{~m}$. Otherwise, at a speed of $V_{\Pi}=2,0 \mathrm{~m} / \mathrm{s}$, the vibration digging mode will be disrupted.

Let's give values of admissible frequencies of oscillation of the working device, it is possible to recommend for a range of speeds of forward movement $1,3 \ldots 2.2 \mathrm{~m} / \mathrm{s}$, taking into account the limitations of the vibrating frequencies of the working device from the conditions of mandatory capture of each root crop by digging ploughshares:

- for the mass point of contact of the working device $m=0,8 \mathrm{~kg}$ : at the depth of movement in the soil $0.08 \mathrm{~m}$ and amplitude of oscillations $0.008 \ldots 0,024 \mathrm{~m}$, permissible vibration frequency is $21,2 \mathrm{~Hz}$; at stroke depth of $0,10 \mathrm{~m}-10,0 \mathrm{~Hz}$; at stroke depth of $0,12 \mathrm{~m}-9,0 \mathrm{~Hz}$;

- for the mass of the working body reduced to the point of contact $m=1,0 \mathrm{~kg}$ : at a stroke depth of $0.08 \mathrm{~m}$ in the soil and the vibration amplitude of $0.008 \ldots 0.024 \mathrm{~m}$, the permissible frequency of vibration is $16.4 \mathrm{~Hz}$; at a stroke depth of $0.10 \mathrm{~m}$ and vibration amplitude of $0.008 \ldots 0,018 \mathrm{~m}$ - the permissible frequency of vibration is $10,0 \mathrm{~Hz}$, at an amplitude of $0,020 \ldots 0,024 \mathrm{~m}-8,3 \mathrm{~Hz}$;

- for the mass point of contact of the working device $m=1.5 \mathrm{~kg}$ : at a depth of $0.08 \mathrm{~m}$ in the soil and the amplitude of vibrations $0.008 \ldots 0.024 \mathrm{~m}$, the permissible frequency of oscillations is $10.0 \mathrm{~Hz}$; at a stroke depth of $0.10 \mathrm{~m}$ and vibration amplitude of $0.008 \ldots 0,010 \mathrm{~m}$ - the permissible vibration frequency is $10,0 \mathrm{~Hz}$, at an amplitude of $0,012 \mathrm{~m}-8,0 \mathrm{~Hz}$. 


\section{Conclusions}

The obtained analytical dependence between the number of vibrations, which will be carried out by the vibrating working body during the stay of the root in the working bed of the digger, the frequency of vibrations of the working body, the length of the back of the working bed and the speed of the progressive movement of the digger, provided a satisfactory process of vibratory digging of sugar beet roots.

Determined the minimum allowable frequencies of vibrations of the working device for specific values of the speed of translational motion Kopach and length of the back part of the working channel, at which at least one delight of the root is possible by vibrating digging out the working device.

With the length of the back of the working channel of the digger $0.1 \mathrm{~m}$ and progressive speed $V_{\Pi}=2,1 \mathrm{~m} / \mathrm{s}$ oscillation frequency $V=20,0 \mathrm{~Hz}$ provides a satisfactory mode of vibratory root digging, and frequencies $V=15,7 \mathrm{~Hz}$ and $\mathrm{V}=8,5 \mathrm{~Hz}$ - provide insufficient, and at the same length of the back part of the working channel and the forward speed of movement $V_{\Pi}=1,3 \mathrm{~m} / \mathrm{s}$ frequency $\mathrm{V}=20,3 \mathrm{~Hz}$ and $\mathrm{V}=15,7 \mathrm{~Hz}$ $\mathrm{Hz}$ provide a satisfactory mode of vibratory root excavation, and frequency $\mathrm{V}=8,5 \mathrm{~Hz}$ provides insufficient, that is, some root crops are not withdrawn by the working body, or cracked at the tail part.

To ensure a satisfactory process of vibratory root excavation at a speed of progressive movement of the digger $V_{\Pi}=2,0 \mathrm{~m} / \mathrm{s}$ and the frequency of vibrations of the working device $\mathrm{V}=10 \mathrm{~Hz}$ it is necessary that the length of the back of the working channel of the digger is equal to $0.2 \mathrm{~m}$.

As a result of numerical calculations the values of admissible frequencies of oscillation of the working device are determined, it is possible to recommend for a range of speeds of forward movement 1.3...2.2 $\mathrm{m} / \mathrm{s}$, taking into account the limitations of the vibrating frequencies of the working device from the conditions of mandatory capture of each root crop digging with a ploughshare.

\section{References}

1. Vasilenko, P.M., Pogorelyy, L.V., \& Brey, V.V. (1970). Vibratsionnyy sposob uborki korneplodov [Vibration method of harvesting root crops]. Mechanization and electrification of socialist agriculture, 2, 9 - 13. [In Russian].

2. Bulhakov, V.M., \& Holovach, I.V. (2003). Teoriia vibratsiinoho vykopuvannia koreneplodiv. Zbirnyk naukovykh prats Natsionalnoho ahrarnoho universytetu "Mekhanizatsiia silskohospodarskoho vyrobnytstva" [Theory of vibratory digging of root crops]. Collection of scientific works of the National Agrarian University "Mechanization of agricultural production", XIV, 34 - 86. [In Ukrainian].

3. Bulhakov, V.M., \& Holovach, I.V. (2004). Teoriia poperechnykh kolyvan koreneplodu pry vibratsiinomu vykopuvanni. [The theory of transverse oscillations of the root during vibration excavation]. Proceedings of the Tavriya State Agrotechnical Academy, 18. Melitopol, 8 - 24. [In Ukrainian].

4. Bulhakov, V.M., \& Holovach, I.V. (2005). Pro vymusheni poperechni kolyvannia tila koreneplodu pry vibratsiinomu vykopuvanni. [On forced transverse oscillations of the root body during vibration excavation]. Bulletin of the Petro Vasylenko Kharkiv National Technical University of Agriculture. Collection of scientific works, 39. Kharkiv: KhNTUSH, 23 - 39. [In Ukrainian].

5. Bulhakov, V., \& Holovach, I. (2006). Rozrobka matematychnoi modeli vyluchennia koreneplodu z gruntu [Development of a mathematical model of root crop extraction from the soil]. APK Technique, 6, 7, 8, 36 - 38. [In Ukrainian].

6. Bulhakov, V.M., \& Holovach, I.V. (2006). Teoretychne doslidzhennia povzdovzhnikh kolyvan koreneplodu u grunti yak u pruzhnomu seredovyshchi pry vibratsiinomu vykopuvanni [Theoretical study of longitudinal oscillations of the root crop in the soil as in an elastic medium during vibration excavation]. Bulletin of the Petro Vasylenko Kharkiv National Technical University of Agriculture. Collection of scientific works, 44(2). Kharkiv: KhNTUSH, 131 - 155. [In Ukrainian].

7. Holovach, I.V. (2006). Teoriia bezposerednoho vyluchennia koreneplodu z gruntu pry vibratsiinomu vykopuvanni [The theory of direct extraction of root crops from the soil by vibration excavation]. Bulletin of the Petro Vasylenko Kharkiv National Technical University of Agriculture. Collection of scientific works, 44(2). Kharkiv: KhNTUSH, 77 - 100. [In Ukrainian].

8. Pogorelyy, L.V., Tatyanko, N.V., Brey, V.V. et al. (L.V. Pogorelyi (Ed.)). (1983). Svekloubochnye mashiny (konstruirovanie i raschet) [Beet-harvesting machines (design and calculation)] Kyiv: Tekhnika. [In Russian].

9. Pogorelyy, L.V., \& Tatyanko, N.V. (2004). Sveklouborochnye mashiny (istoriya, konstruktsiya, teoriya, prognoz) [Beet harvesters (history, design, theory, forecast)]. Kyiv: Feniks. [In Russian].

10. Boson, E.S., Verniaev, O.V., Smirnov, I.I. \& Sultan-Shach, E.G. (2019). Theory, Construction and Calculation of Agricultural Machines. 2nd Ed., Scientific Publisher.

11. Gu, F., Hu, Z., Wu, H., Peng, B., Gao, X. \& Wang, S. (2014). Development and experiment of 4LT-A staggered-dig sugar beet combine. Nongye Gongcheng Xuebao. Transactions of the Chinese Society of Agricultural Engineering, 30(23), 1-9. 
12. Schmitz, T.L. \& Smith, K.S. (2012). Mechanical vibrations: Modeling and measurement. Springer.

13. Schulze Lammers, P. (2011). Harvest and loading machines for sugar beet - new trends. International Sugar Journal, 113(1348), 253-256.

14. Schulze Lammers, P.S. \& Schmittmann, O. (2013). Testing of sugar beet harvesters in Germany 2012. International Sugar Journal, 115(1370), 100-106. 